\title{
Body fluid status assessment by bio-impedance analysis in patients presenting to the emergency department with dyspnea
}

\author{
Chan Soon Park, Sang-Eun Lee, Hyun-Jai Cho, Yong-Jin Kim, Hyun-Jae Kang, Byung-Hee Oh, and \\ Hae-Young Lee
}

Department of Internal Medicine, Seoul National University Hospital, Seoul, Korea

Received: November 11, 2016 Revised : January 31, 2017

Accepted: March 11, 2017

\section{Correspondence to}

Hae-Young Lee, M.D.

Department of Internal Medi-

cine, Seoul National University Hospital, 101 Daehak-ro, Jongnogu, Seoul 03080, Korea

Tel: $+82-2-2072-0698$

Fax: +82-2-3674-0805

E-mail: hylee612@snu.ac.kr
Background/Aims: Fluid retention occurs in patients with heart failure, accounting for dyspnea. We investigated the diagnostic implication of body fluid status, assessed by bio-impedance analysis (BIA), in acute heart failure (AHF) among patients who presented with dyspnea.

Methods: A total of 100 patients who presented with dyspnea and suspected with AHF were analyzed in this study. We enrolled 50 AHF and 50 non-AHF patients discriminated through echocardiographic analysis and Framingham criteria and were matched by age and sex. Body composition was analyzed using a multifrequency BIA.

Results: AHF patients demonstrated higher extracellular water (ECW)/total body water (TBW) compared with non-AHF patients ( $0.412 \pm 0.017$ vs. $0.388 \pm 0.023, p$ $<0.001$ ). A significant difference of ECW/TBW between AHF patients and nonAHF patients was noted when the upper extremities, trunk, and lower extremities were analyzed (all $p<0.001$, respectively). ECW/TBW was not different between patients with reduced ejection fraction (EF) and preserved EF along body compartments. The best cut-off value to predict AHF was $>0.412$ at lower extremities with sensitivity and specificity of 0.780 and 0.960 . The ECW/TBW of the lower extremities $\left(\mathrm{ECW} / \mathrm{TBW}_{\mathrm{L}}\right)$ was correlated with $\log$ B-type natriuretic peptide (BNP) levels $(r=0.603, p<0.001)$ and also improved the net reclassification improvement and integrated discriminated improvement when added to log BNP level. Multivariate analysis revealed that $\mathrm{ECW} / \mathrm{TBW}_{\mathrm{L}}>0.412 \mathrm{had}$ an independent association with AHF patients $(p=0.011)$.

Conclusions: The ECW/TBW $\mathrm{L}_{\mathrm{L}}$ was higher in patients with dyspnea caused by AHF than their counterparts and demonstrated an independent diagnostic implication. It may be a promising marker to diagnose AHF at bedside.

Keywords: Heart failure; Electric impedance; Dyspnea; Natriuretic peptide, brain

\section{INTRODUCTION}

Fluid and sodium retention is considered as an important pathophysiologic mechanism in heart failure (HF)
$[1,2]$. It leads to cardinal symptoms and signs of HF, such as dyspnea, pulmonary congestion, pitting edema, and elevated jugular venous pressure $[3,4]$. As volume overload is associated not only with clinical manifestations 
but also with an increased risk of hospitalization and mortality [5-7], decongestive treatment with diuretics for optimal volume status is essential for HF management $[3,4,8,9]$.

The golden standard method of volume status evaluation is measuring pulmonary capillary wedge pressure and right atrial pressure by cardiac catheterization [10]. Echocardiography and natriuretic peptide level measurement are also used to evaluate the volume status $[3,11]$, and are typically performed early for patients suspected with HF with acute onset [3]. However, their clinical use might be affected by invasiveness, training proficiency of clinician, cost, and accessibility. Bio-impedance analysis (BIA) with a body composition analyzer is a noninvasive method that can be performed at the bedside. The multifrequency analyzer advancement enables accurate analysis of body composition, which includes extracellular water (ECW) and intracellular water (ICW) $[12,13]$. BIA has recently proven its efficacy in various volume overload conditions, including renal failure, liver cirrhosis, and HF [14-17], and its clinical application possibility has been implicated in patients with dyspnea [15,18]. Only few studies distinguished patients with acute heart failure (AHF) from those without AHF based on BIA [15]. In addition, data that distinguish dyspnea patients based on water distribution upon body segments are scarce.

In this study, the diagnostic implication of body fluid status, assessed by BIA, in AHF among patients who presented with dyspnea in the emergency department was evaluated.

\section{METHODS}

\section{Study population}

Patients who presented in the emergency department of Seoul National University Hospital with dyspnea as the chief complaint from January 2015 to March 2016 were screened. Transthoracic echocardiography was performed in order to discriminate AHF patients. Patients with coronary artery disease who presented mainly with dyspnea, not chest pain, were included. Those who had $\mathrm{HF}$ (ejection fraction $[\mathrm{EF}]<50 \%$ or $\mathrm{EF} \geq 50 \%$ with peak velocity of transmitral early diastolic left ventricular filling/early diastolic annular velocity $\left[\mathrm{E} / \mathrm{e}^{\prime}\right]>$ 15) and who met the Framingham criteria were diagnosed with AHF [19]. After proper evaluation based on a previous study [11], a diagnosis other than AHF was made considering the following: normal chest X-ray; X-ray suspicious for lung cancer, pneumonia, or chronic obstructive lung disease; normal cardiac function confirmed by transthoracic echocardiography; and improved symptoms after nebulization and corticosteroid or antibiotic treatment. BIA and transthoracic echocardiography were performed in the emergency department by different clinicians blinded to the results. The tests were performed with a <10-minute interval. A written informed consent was obtained from the patients prior to the BIA and transthoracic echocardiography. Fifty patients diagnosed with AHF and 50 patients with other etiologies were enrolled. Additional 50 patients who underwent echocardiography for preoperative cardiac evaluation for elective surgery, baseline cardiac evaluation before chemotherapy, or post-stroke cardiac evaluation were also analyzed as the non-dyspnea group to suggest the control value of BIA. This study was approved by the Institutional Review Board of Seoul National University Hospital (IRB No. 1501-122-647) and conformed to the principles outlined in the Declaration of Helsinki.

\section{Clinical data collection and BIA}

The patients' baseline demographic data, underlying diseases, and laboratory test results were collected from the electronic medical records of Seoul National University Hospital. Medical history included diabetes mellitus, hypertension, chronic kidney disease including end-stage renal disease, liver cirrhosis, and atrial fibrillation. Information on following typical symptoms and signs that could implicate the volume overload status or AHF were also collected: orthopnea, rales, pretibial edema, and pulmonary congestion on chest radiography. Data on leukocyte, hemoglobin, platelet, blood urea nitrogen, creatinine, serum sodium, albumin, and B-type natriuretic peptide (BNP) levels measured at admission were also obtained for this study. Blood sampling and tests were performed as routine practice by laboratories certified by the Korean Association of Quality Assurance for Clinical Laboratory. Echocardiography was performed using commercially available systems. Echocardiographic variables included E (peak velocity of transmitral early diastolic left ventricular [LV] filling), 
EDT (E-deceleration time), e' (early diastolic annular velocity), E/e', LV EF, LV internal diameter in diastole and systole, LV interventricular septum and posterior wall thickness, and LV mass index.

BIA was performed using the portable multifrequency bio-impedance device (InBody S1o, InBody Co. Ltd., Seoul, Korea) (Fig. 1A). With the 8-point touch type electrodes prepared according to the manufacturer's instructions, the analyzer measured the segmental resistance at multiple frequencies $(1,5,50,250,500 \mathrm{kHz}$, and $1 \mathrm{MHz}$ ). Multifrequency BIA have proven their efficacy in predicting the ICW and ECW compartments of total body water (TBW), and the accuracy was comparable to dual-energy X-ray absorptiometry [20-22]. The body served as a cylindrical conductor with a constant cross-sectional area. At low-level frequencies, the cell membrane acted as an insulator and the current flowed predominantly through the ECW; consequently, ECW resistance was recorded. At high-level frequencies, the current could penetrate the cell membrane; thus, ICW and ECW resistance were determined [23]. The device can estimate the body fluid status using the data obtained and previously determined constants [12,24]. Based on the segmental data of the four limbs, the parameters of lower and upper extremities were calculated and used in this study. Measured data were automatically stored in the BIA and could be printed as Fig. 1B.

\section{Statistical analysis}

Data were presented as numbers and frequencies for categorical variables, and as mean with standard deviation or median with interquartile ranges for continuous variables. For comparison between groups, the chisquare test (or Fisher exact test when expected cell count was $<5$ for a $2 \times 2$ table) and unpaired Student $t$ test were used for continuous variables and categorical variables, respectively. The ECW/TBW difference from the different segments of the same patient was compared by a paired $t$ test. A receiver operating characteristic (ROC) curve analysis was used to determine the optimal ECW/
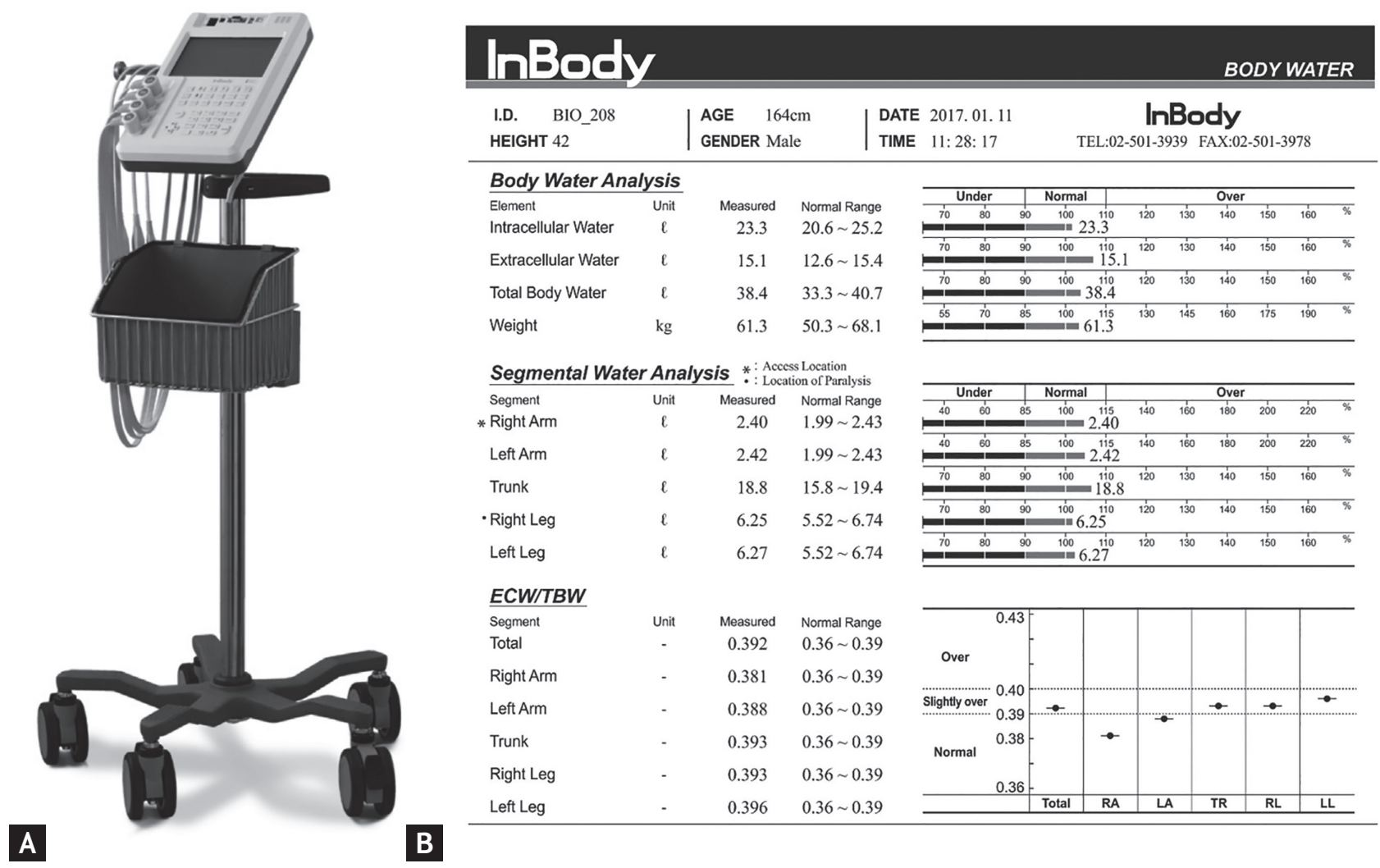

Figure 1. Bio-impedance device (A) and an example of analysis (B). The portable multifrequency bio-impedance device (InBody S1o, InBody Co. Ltd.) was adopted in this study. With this tool, the data of body composition could be acquired within a minute at bedside. 
TBW cut-off value by maximizing the sum of sensitivity and specificity. Category-free net reclassification index and integrated discrimination improvement analyses were performed. ECW/TBW was incorporated to $\log$ BNP level to demonstrate the additional predictive value of ECW/TBW in comparison with that of evaluation with log BNP level alone for AHF. A multivariable logistic regression model was used to identify the independent factors associated with AHF diagnosis, and variables associated with $\mathrm{AHF}$ that had $p$ values of $<0.05$ in the univariate analysis were included as confounding factors in the multivariate analysis. A two-sided $p<0.05$ was considered statistically significant. As this analysis was an explorative study, no $\alpha$ adjustment was conducted. Statistical tests were performed using IBM SPSS version 22.0 (IBM Corp., Armonk, NY, USA).

\section{RESULTS}

\section{Baseline characteristics of the subjects}

Baseline characteristics according to the diagnosis are presented in Table 1. Dyspneic patients diagnosed with AHF had a higher prevalence of diabetes mellitus and atrial fibrillation, higher BNP levels, and larger left atrium diameter, LV internal diameter in diastole, and LV mass index, whereas the EF level was significantly lower than that of patients without AHF. Among the patients without atrial fibrillation, the patients with AHF had a higher E/e' level $(20.6 \pm 8.8$ vs. $9.7 \pm 2.8, p<0.001)$ than their counterparts, but this association was not significant among the 14 patients with atrial fibrillation (15.4 \pm 5.5 vs. $8.9 \pm 0.9, p=0.140$ ). Patients without AHF had the following diagnoses: unstable angina, pulmonary thromboembolism, pneumonia, anemia with or without hematologic malignancy, liver cirrhosis, malignancy with hypoalbuminemia, etc. A comparison of baseline characteristics with the non-dyspnea group is presented in Supplementary Table 1. Among AHF group, $23 \mathrm{AHF}$ patients had a reduced $\mathrm{EF}$ and 27 demonstrated a preserved EF. Patients with reduced EF demonstrated longer LV internal diameter in diastole $(59.3 \pm 9.5 \mathrm{~mm}$ vs. $48.6 \pm 7.2 \mathrm{~mm}, p<0.001)$ and higher LV mass index (137.9 $\pm 46.9 \mathrm{~g} / \mathrm{m}^{2}$ vs. $98.6 \pm 45.1 \mathrm{~g} / \mathrm{m}^{2}, p=0.012$ ). Of the patients, 38 did not have atrial fibrillation, and their E (1.0 \pm 0.2 $\mathrm{m} / \mathrm{s}$ vs. $1.0 \pm 0.4 \mathrm{~m} / \mathrm{s}, p=0.923)$, EDT $(154.5 \pm 22.1 \mathrm{msec}$ vs.
$175.5 \pm 63.3 \mathrm{msec}, p=0.228)$, e' $(5.1 \pm 1.8 \mathrm{~cm} / \mathrm{sec}$ vs. $5.7 \pm 2.1$ $\mathrm{cm} / \mathrm{sec}, p=0.337)$, and $\mathrm{E} / \mathrm{e}^{\prime}$ values $(22.2 \pm 8.1$ vs. $18.8 \pm 9.4$, $p=0.240$ ) were comparable between the patients with reduced and preserved EF. Among the patients with reduced EF, only the two patients had atrial fibrillation.

\section{Comparison of body fluid status between AHF pa- tients and non-AHF patients}

Segmental water distribution analyzed by BIA is presented in Table 2. Weight, TBW, and ICW were similar among groups, but AHF patients had increased ECW compared with non-AHF patients (Fig. 2A). The ECW/ TBW ratio was comparable between the non-dyspnea and non-AHF groups, while the ratio was significantly different between the non-dyspnea and AHF groups across the body segments (Supplementary Table 2). The ECW to TBW ratio between AHF patients and non-AHF patients was also significantly different, and this difference was persistently observed when the upper extremities $\left(\mathrm{ECW} / \mathrm{TBW}_{\mathrm{U}}\right)$, trunk $\left(\mathrm{ECW} / \mathrm{TBW}_{\mathrm{T}}\right)$, and lower extremities $\left(\mathrm{ECW} / \mathrm{TBW}_{\mathrm{L}}\right)$ were analyzed separately. ECW/ $\mathrm{TBW}_{\mathrm{L}}$ was higher than ECW/TBW $\mathrm{U}_{\mathrm{U}}$ in both AHF and non-AHF patients $(p<0.001$ ) (Fig. $2 B$ ). No significant difference was noted between AHF patients with a reduced $\mathrm{EF}$ and those with a preserved EF in ECW/TBW (0.409 \pm 0.018 vs. $0.415 \pm 0.016, p=0.166), \mathrm{ECW} / \mathrm{TBW}_{\mathrm{U}}(0.388 \pm$ 0.007 vs. $0.388 \pm 0.017, p=0.959), \mathrm{ECW} / \mathrm{TBW}_{\mathrm{T}}(0.409 \pm$ 0.018 vs. $0.416 \pm 0.016, p=0.124)$, and $\mathrm{ECW} / \mathrm{TBW}_{\mathrm{L}}(0.415$ \pm 0.021 vs. $0.423 \pm 0.018, p=0.134$ ) (Supplementary Fig. 1). The predictive values of orthopnea, pretibial edema, rale, and pulmonary congestion on chest radiography are presented in Table 3. Among these parameters, pretibial edema showed a sensitivity and specificity of 0.720 and 0.920 , respectively. In all the patient groups, significant differences were found for ECW/TBW ${ }_{\mathrm{U}}(0.391$ \pm 0.007 vs. $0.380 \pm 0.011, p<0.001), \mathrm{ECW} / \mathrm{TBW}_{\mathrm{T}}(0.417 \pm$ 0.013 vs. $0.390 \pm 0.020, p<0.001)$, and $\mathrm{ECW} / \mathrm{TBW}_{\mathrm{L}}(0.423$ \pm 0.016 vs. $0.392 \pm 0.026, p<0.001)$ based on the presence of pretibial edema.

\section{The relationship of ECW/TBW with AHF in dyspnea patients}

$\mathrm{ECW} / \mathrm{TBW}_{\mathrm{L}}$ and log BNP level $(r=0.603, p<0.001)$ was significantly correlated. On the contrary, ECW/TBW ${ }_{\mathrm{L}}$ was not significantly associated with body mass index $(r=-0.145, p=0.149)$, systolic and diastolic blood pressure 
Table 1. Baseline characteristics according to the diagnosis of AHF

\begin{tabular}{|c|c|c|c|}
\hline Characteristic & $\operatorname{AHF}(\mathrm{n}=50)$ & Non-AHF $(n=50)$ & $p$ value \\
\hline \multicolumn{4}{|l|}{ Demographic data } \\
\hline Age, yr & $70.2 \pm 11.3$ & $66.1 \pm 11.6$ & 0.077 \\
\hline$\geq 65 \mathrm{yr}, \%$ & 66.0 & 58.0 & 0.300 \\
\hline Men, \% & 50.0 & 52.0 & 0.841 \\
\hline Body mass index, $\mathrm{kg} / \mathrm{m}^{2}$ & $24.2 \pm 4.1$ & $24.6 \pm 3.4$ & 0.590 \\
\hline \multicolumn{4}{|l|}{ Past medical history, \% } \\
\hline Diabetes mellitus & 34.0 & 14.0 & 0.019 \\
\hline Hypertension & 50.0 & 54.0 & 0.689 \\
\hline Chronic kidney disease and end stage renal disease & 24.0 & 12.0 & 0.118 \\
\hline Liver cirrhosis & o & 4.0 & 0.153 \\
\hline Atrial fibrillation & 24.0 & 4.0 & 0.004 \\
\hline \multicolumn{4}{|l|}{ Laboratory findings } \\
\hline Leukocyte, / $\mu \mathrm{L}$ & $7,701.8 \pm 3,412.3$ & $7,680.5 \pm 4,401.4$ & 0.979 \\
\hline Hemoglobin, mg/dL & $11.8 \pm 2.4$ & $12.3 \pm 2.6$ & 0.294 \\
\hline Platelet, $\times 10^{3} / \mu \mathrm{L}$ & $176.3 \pm 97.8$ & $195.2 \pm 81.6$ & 0.298 \\
\hline Blood urea nitrogen, mg/dL & $23.7 \pm 22.4$ & $18.7 \pm 13.8$ & 0.038 \\
\hline Creatinine, $\mathrm{mg} / \mathrm{dL}$ & $1.8 \pm 2.1$ & $1.3 \pm 1.8$ & 0.170 \\
\hline Glomerular filtration rate, $\mathrm{mL} / \mathrm{min} / 1.73 \mathrm{~m}^{2}$ & $56.0 \pm 29.1$ & $71.7 \pm 26.8$ & 0.007 \\
\hline Sodium, mEq/L & $138.2 \pm 5.0$ & $140.5 \pm 2.4$ & 0.004 \\
\hline Protein, g/dL & $6.52 \pm 0.73$ & $6.95 \pm 0.59$ & 0.002 \\
\hline Albumin, g/dL & $3.64 \pm 0.48$ & $3.93 \pm 0.52$ & 0.005 \\
\hline B-natriuretic peptide, $\mathrm{pg} / \mathrm{mL}$ & $1,108.0(288.0-2,372.5)$ & $34.5(17.5-90.3)$ & $<0.001$ \\
\hline \multicolumn{4}{|l|}{ Vital sign } \\
\hline Systolic blood pressure, $\mathrm{mmHg}$ & $142.4 \pm 28.5$ & $139.6 \pm 33.7$ & 0.650 \\
\hline Diastolic blood pressure, $\mathrm{mmHg}$ & $81.6 \pm 17.0$ & $80.3 \pm 19.2$ & 0.713 \\
\hline Heart rate, /min & $93.7 \pm 22.5$ & $83.3 \pm 21.4$ & 0.020 \\
\hline Respiratory rate, /min & $20.6 \pm 3.2$ & $19.4 \pm 2.5$ & 0.046 \\
\hline \multicolumn{4}{|l|}{ Echocardiographic data } \\
\hline $\mathrm{E}, \mathrm{m} / \mathrm{sec}$ & $1.0 \pm 0.3$ & $0.7 \pm 0.2$ & $<0.001$ \\
\hline EDT, msec & $159.6 \pm 46.7$ & $199.2 \pm 57.7$ & 0.001 \\
\hline $\mathrm{e}^{\prime}, \mathrm{cm} / \mathrm{sec}$ & $6.1 \pm 2.5$ & $7.1 \pm 2.4$ & 0.082 \\
\hline $\mathrm{E} / \mathrm{e}^{\prime}$ & $19.4 \pm 8.4$ & $9.7 \pm 2.7$ & $<0.001$ \\
\hline Left atrium diameter, $\mathrm{mm}$ & $51.3 \pm 15.0$ & $41.1 \pm 6.6$ & $<0.001$ \\
\hline LV ejection fraction, \% & $47 \cdot 5 \pm 14 \cdot 4$ & $58.8 \pm 5.5$ & $<0.001$ \\
\hline LV internal diameter in diastole, $\mathrm{mm}$ & $53 \cdot 5 \pm 9.8$ & $48.3 \pm 4.4$ & 0.001 \\
\hline LV internal diameter in systole, $\mathrm{mm}$ & $37.6 \pm 10.6$ & $31.1 \pm 4.1$ & 0.003 \\
\hline LV interventricular septum thickness, mm & $9 \cdot 3 \pm 2.1$ & $8.9 \pm 1.7$ & 0.347 \\
\hline LV posterior wall thickness, mm & $9.8 \pm 5.6$ & $8.3 \pm 1.4$ & 0.062 \\
\hline LV mass index, $\mathrm{g} / \mathrm{m}^{2}$ & $112.9 \pm 49.1$ & $85.6 \pm 19.8$ & 0.002 \\
\hline
\end{tabular}

Values are presented as mean \pm standard deviation or median (interquartile range).

AHF, acute heart failure; E, peak velocity of transmitral early diastolic left ventricular filling; EDT, E-deceleration time; e', early diastolic annular velocity; LV, left ventricle. 
$(r=0.034, p=0.735$ and $r=0.043, p=0.671$, respectively $)$, leukocyte count $(r=0.065, p=0.518)$, serum sodium concentration $(r=-0.135, p=0.186)$, and albumin level $(r=$ $-0.107, p=0.293)$. ECW/TBW ${ }_{L}$ was significantly associated with $\mathrm{E} / \mathrm{e}^{\prime}(r=0.321, p=0.003)$ in the patients without atrial fibrillation, whereas the significance was attenuated in 14 patients with atrial fibrillation $(r=0.035, p=$ 0.910).
When incorporating ECW/TBW ${ }_{\mathrm{L}}$ as continuous variables with log BNP level, it significantly improved the measures of reclassification. For predicting AHF, incorporating $\mathrm{ECW} / \mathrm{TBW}_{\mathrm{L}}$ with log BNP level did not show significant improvement in area under the curve (AUC from 0.918 to $0.958, p=0.210$ ). However, with ECW/ $\mathrm{TBW}_{\mathrm{L}}$, net reclassification improvement (total value, 1.139; $p<0.001$ ) showed a more significant increment

Table 2. Body fluid distribution according to the diagnosis of $\operatorname{AHF}(n=100)$

\begin{tabular}{|c|c|c|c|}
\hline Variable & $\operatorname{AHF}(\mathrm{n}=50)$ & Non-AHF $(n=50)$ & $p$ value \\
\hline Weight, kg & $62.6 \pm 13.0$ & $63.0 \pm 11.0$ & 0.883 \\
\hline TBW, L & $33.7 \pm 8.3$ & $32.0 \pm 6.6$ & 0.262 \\
\hline ICW, L & $19.8 \pm 5.0$ & $19.6 \pm 4.6$ & 0.877 \\
\hline ECW, L & $13.9 \pm 3.5$ & $12.3 \pm 2.3$ & 0.010 \\
\hline ECW/TBW & $0.412 \pm 0.017$ & $0.388 \pm 0.023$ & $<0.001$ \\
\hline ECW/TBW of upper extremities & $0.388 \pm 0.013$ & $0.380 \pm 0.007$ & $<0.001$ \\
\hline ECW/TBW of trunk & $0.413 \pm 0.017$ & $0.389 \pm 0.020$ & $<0.001$ \\
\hline ECW/TBW of lower extremities & $0.419 \pm 0.020$ & $0.390 \pm 0.026$ & $<0.001$ \\
\hline
\end{tabular}

Values are presented as mean \pm standard deviation.

AHF, acute heart failure; TBW, total body water; ICW, intracellular water; ECW, extracellular water.
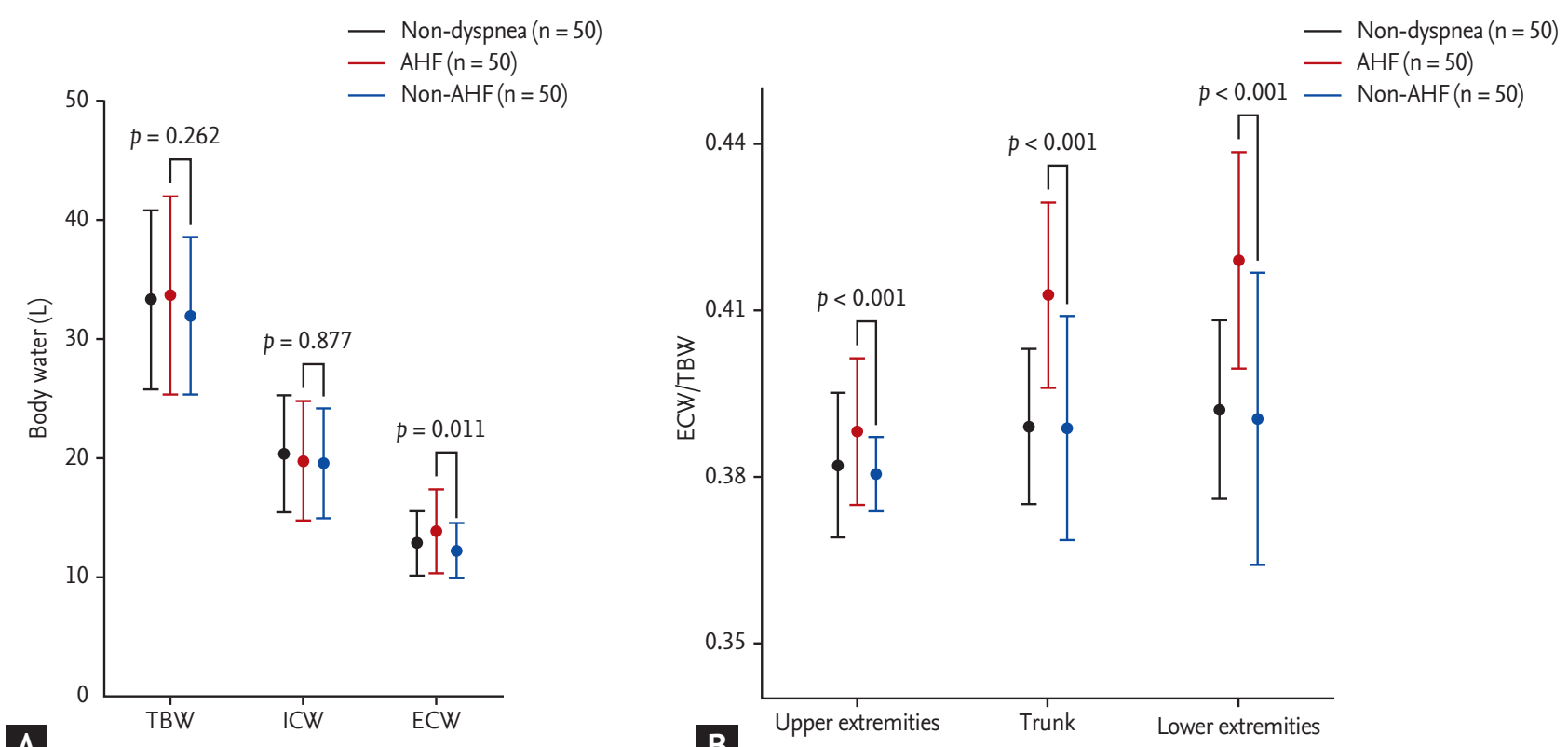

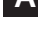

Figure 2. Comparison of water distribution (A), and association between ECW/TBW and body compartments (B) among the non-dyspnea, non-AHF, and AHF groups. The AHF patients (red) and patients with non-AHF etiologies (blue) had similar TBW and ICW, while the patients with AHF had significantly more ECW. Segmental ECW/TBW was persistently higher in the AHF patients. Values for the non-dyspnea group (black) are also presented. AHF, acute heart failure; TBW, total body water; ICW, intracellular water; ECW, extracellular water. 
than when AHF diagnosis was classified with log BNP level. The integrated discriminated improvement of adding $\mathrm{ECW} / \mathrm{TBW}_{\mathrm{L}}$ to the log BNP level also demonstrated a more significant increase (value, $0.131 ; p=0.016$ ) than that with evaluation based on log BNP level.

Univariate logistic regression analysis showed that patients with $\mathrm{ECW} / \mathrm{TBW}_{\mathrm{L}}>0.412$ demonstrated a significant association with AHF diagnosis $(p<0.001)$. As presented in Table 4, the relationship between AHF and increased $\mathrm{ECW} / \mathrm{TBW}_{\mathrm{L}}$ was also significant in the multivariate analysis (odds ratio, 56.627; 95\% confidence interval, 2.519 to $1,272.838$ ).

Fig. 3 shows that ECW/TBW ${ }_{L}$ had the highest AUC in the ROC curve analysis across the body segments, whereas the difference was not statistically significant between

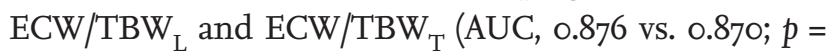
0.263 ) and between $\mathrm{ECW} / \mathrm{TBW}_{\mathrm{L}}$ and $\mathrm{ECW} / \mathrm{TBW}_{\mathrm{U}}(\mathrm{AUC}$, 0.876 vs. $0.826 ; p=0.234)$. The best cut-off value of ECW/ $\mathrm{TBW}_{\mathrm{L}}$ was 0.412 with an AUC, sensitivity, and specificity of $0.876,0.780$, and 0.960 , respectively. Using this cutoff value, 41 patients were diagnosed with AHF (Table 3).
Two false-positive cases were identified: a buccal cancer patient suffering from atypical pneumonia and hypoalbuminemia and a non-small cell lung cancer patient with deep vein thrombosis. The latter patient had a relatively low $\mathrm{ECW} / \mathrm{TBW}_{\mathrm{U}}(0.378)$, whereas the former had elevated ECW/TBW $\mathrm{U}_{\mathrm{U}}$ level (0.391).

\section{DISCUSSION}

In this study, we found that patients presenting with dyspnea and diagnosed with AHF had higher ECW/ TBW than non-AHF patients. We also showed the body water distribution difference between AHF and nonAHF patients. In addition, ECW/TBW ${ }_{L}$ was most significantly associated with AHF diagnosis. Lastly, increased $\mathrm{ECW} / \mathrm{TBW}_{\mathrm{L}}$ was independently related to AHF in the multivariate analysis.

Water is the main composite of the human body. Homeostasis of TBW, of which $55 \%$ to $65 \%$ is distributed in the ICW and $35 \%$ to $45 \%$ in the ECW [25] is maintained

Table 3. Sensitivity and specificity of history, physical findings, and chest radiography for diagnosis of acute heart failure

\begin{tabular}{lcccc}
\hline Variable & Sensitivity & Specificity & Positive predictive value & Negative predictive value \\
\hline Orthopnea & 0.280 & 0.900 & 0.737 & 0.557 \\
Pretibial edema & 0.720 & 0.920 & 0.900 & 0.767 \\
Rale & 0.420 & 0.900 & 0.807 & 0.608 \\
Pulmonary congestion & 0.680 & 0.860 & 0.829 & 0.729 \\
Bio-impedance analysis & 0.780 & 0.960 & 0.951 & 0.814 \\
\hline
\end{tabular}

Table 4. Association of acute heart failure diagnosis with $\mathrm{ECW} / \mathrm{TBW} \mathrm{L}_{\mathrm{L}}$ in multivariate logistic regression analysis

\begin{tabular}{|c|c|c|c|c|c|c|}
\hline \multirow{2}{*}{ Variable } & \multicolumn{3}{|c|}{ Univariate Cox analysis } & \multicolumn{3}{|c|}{ Multivariate Cox analysis } \\
\hline & HR & $95 \%$ Confidence interval & $p$ value & HR & $95 \%$ Confidence interval & $p$ value \\
\hline Age, $\geq 65 \mathrm{yr}$ & 1.539 & $0.679-3.485$ & 0.302 & & & \\
\hline Male sex & 1.083 & $0.494-2.373$ & 0.841 & & & \\
\hline Hypertension & 0.852 & $0.388-1.868$ & 0.689 & & & \\
\hline Diabetes mellitus & 3.165 & $1.176-8.518$ & 0.023 & 1.509 & $0.025-92.094$ & 0.844 \\
\hline Myocardial infarction & 2.042 & $0.179-23.266$ & 0.565 & & & \\
\hline Serum sodium $<135 \mathrm{mEq} / \mathrm{L}$ & 6.409 & $0.742-55.383$ & 0.091 & & & \\
\hline $\mathrm{GFR}<60 \mathrm{~mL} / \mathrm{min} / 1.73 \mathrm{~m}^{2}$ & 4.109 & $1.739-9.713$ & 0.001 & 18.066 & $0.432-755.739$ & 0.129 \\
\hline $\mathrm{BNP} \geq 100 \mathrm{pg} / \mathrm{mL}$ & 25.000 & $4.850-128.856$ & $<0.001$ & 30.304 & $1.577-582.517$ & 0.024 \\
\hline $\mathrm{ECW} / \mathrm{TBW}_{\mathrm{L}}>0.412$ & 85.091 & $17.796-406.886$ & $<0.001$ & 56.627 & $2.519-1272.838$ & 0.011 \\
\hline
\end{tabular}

$\mathrm{ECW} / \mathrm{TBW}_{\mathrm{L}}$, the ratio of extracellular water to total body water in lower extremities; HR, hazard ratio; GFR, glomerular filtration rate; BNP, B-type natriuretic peptide. 


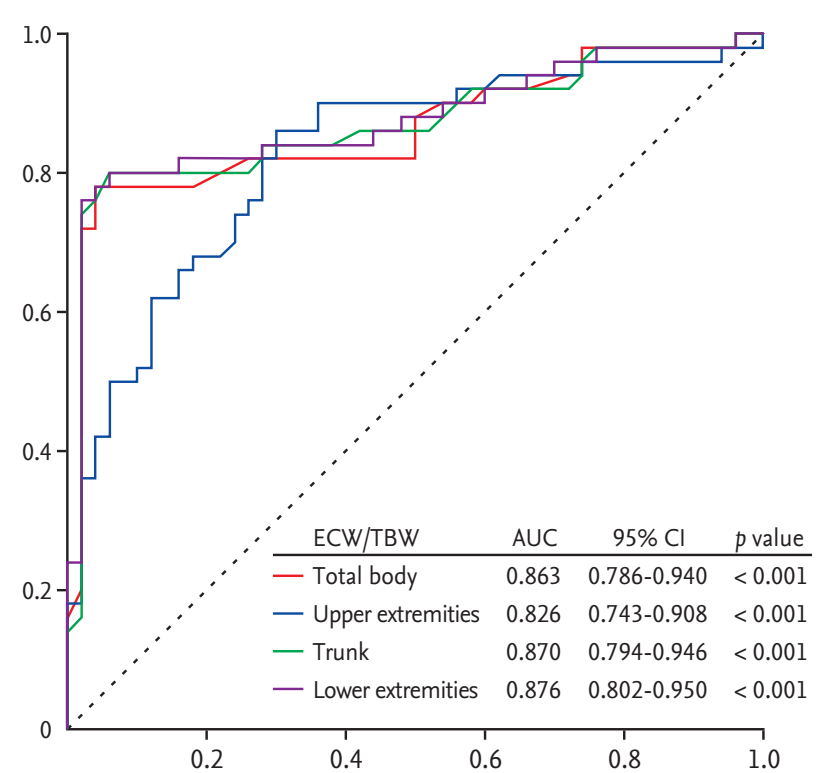

Figure 3. Receiver operating characteristics curve analysis. In receiver operating characteristics curve analysis, the AUC of ECW/TBW to predict acute heart failure were presented, according to body compartments. ECW, extracellular water; TBW, total body water; AUC, area under the curve; CI, confidence interval.

by water and sodium metabolism, but it could be altered in various pathologic conditions, such as congestive $\mathrm{HF}$, characterized by increased ECW volume [26,27]. This pathologic change results in the typical characteristics of HF: increased cardiac filling pressure causes jugular venous distension, pulmonary congestion, dyspnea [28], and ventricular overloads, which trigger the synthesis of BNP [29,30]. In previous studies, cardiac catheterization, echocardiography, and BNP level have proven their clinical value in diagnosing and managing HF by identifying the volume status of the patients [10,11,31-33]. However, invasiveness and cost became the significant barriers in their clinical application. With the recent advancement of multifrequency BIA [34,35] and because of its cost-effectiveness, accuracy, and turnaround time, it has become comparable to dual-energy X-ray absorptiometry [20-22] and could be useful in evaluating the volume status of HF patients at the bedside [15].

$\mathrm{ECW} / \mathrm{TBW}$ is significantly increased in AHF patients, and in this study, ECW/TBW obtained from the lower extremities has superior predictive value compared with that obtained from other parts. Interestingly, both AHF and non-AHF patients showed increased $\mathrm{ECW} / \mathrm{TBW}_{\mathrm{L}}$.

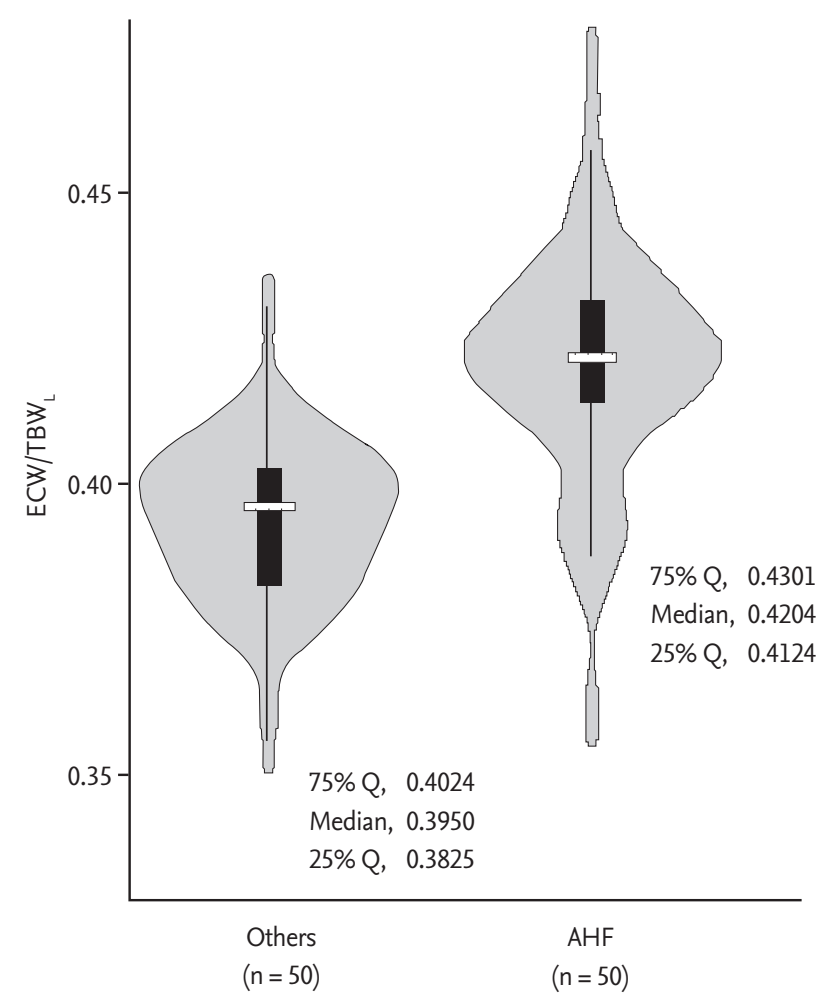

Figure 4. Violin plots showing the distribution of ECW/ $\mathrm{TBW}_{\mathrm{L}}$ in patients with or without AHF. The density trace of violin plots shows the ECW/TBW ${ }_{L}$, while the box plots inside represent the summary statistics. ECW/TBW $\mathrm{L}$, the ratio of extracellular water to total body water of lower extremities; AHF, acute heart failure.

ECW is subdivided into the interstitial water and plasma water, and the disposition is regulated by Starling forces and other determinants [36,37]. In the dependent position, gravity enhances the hydrostatic pressure in the blood vessels, which leads to the increase of transcapillary filtration $[38,39]$. All patients in this study were ambulatory; therefore, plasma water filtration and accumulation in the interstitium might have been augmented in the lower extremities. In AHF patients, increased level of neurohormonal activity contributes to sodium and water retention, which further leads to additional increase of ECW. Considering these findings, it can be speculated that $\mathrm{ECW} / \mathrm{TBW}_{\mathrm{L}}$ is higher compared with $\mathrm{ECW} / \mathrm{TBW}_{\mathrm{U}}$ regardless of AHF diagnosis, and $\mathrm{ECW} /$ $\mathrm{TBW}_{\mathrm{L}}$ is much more increased in AHF patients (Fig. 4); therefore, the discrepancy between the groups was most prominent in the lower extremities of AHF patients.

Pulmonary and systemic congestions, most often the result of high LV diastolic pressures, could present as 
various findings, including pulmonary and pretibial edema. These findings are typically observed in both patients with AHF and those with advanced HF [40]. Increased LV diastolic pressure could cause pulmonary edema just before pretibial edema, which are both markers of interstitial fluid. However, intravascular fluid status might change nearly simultaneously. In this study, AUC for predicting AHF was comparable and even higher at the lower extremities compared to the trunk. We suggest that BIA rather than physical examination predicted the overloaded status of ECW in advance, which comprises the interstitial and intravascular fluids, owing to the overlapping hydrostatic pressure. Using $\mathrm{ECW} / \mathrm{TBW}_{\mathrm{U}}$ in addition to $\mathrm{ECW} / \mathrm{TBW}_{\mathrm{L}}$ might help reduce the possibility of false-positive results such as deep-vein thrombosis.

Our study has several limitations. This single center, prospective, exploratory study included a relatively small number of patients; therefore, an unmeasured bias could have influenced this study. In addition, we only included patients who could undergo echocardiography in the emergency department; thus, critically ill patients were not included.

In conclusion, $\mathrm{ECW} / \mathrm{TBW}_{\mathrm{L}}$ in $\mathrm{AHF}$ patients is significantly increased compared with that in non-AHF patients and is significantly correlated with log BNP level. It has an independent clinical value for AHF diagnosis among patients with dyspnea suspected of having AHF. Considering the rapid evaluation and diagnostic accuracy, body fluid status assessment by BIA may be a promising tool in diagnosing AHF.

\section{KEY MESSAGE}

1. In acute heart failure (AHF) patients, the ratio of extracellular water divided by total body water (ECW/TBW) is significantly increased in all segments, especially in lower extremities.

2. Among the body compartments, ECW/TBW of lower extremities has the most accurate predictive power for AHF. With the reference value of 0.412 , the sensitivity and specificity are 0.780 and 0.960 , respectively.

3. In multivariate analysis, increased level of ECW/ TBW > 0.412 from lower extremities is an independent diagnostic marker for AHF diagnosis.

\section{Conflict of interest}

No potential conflict of interest relevant to this article was reported.

\section{REFERENCES}

1. Schrier RW. Role of diminished renal function in cardiovascular mortality: marker or pathogenetic factor? J Am Coll Cardiol 2006;47:1-8.

2. Cotter G, Metra M, Milo-Cotter O, Dittrich HC, Gheorghiade M. Fluid overload in acute heart failure: re-distribution and other mechanisms beyond fluid accumulation. Eur J Heart Fail 2008;10:165-169.

3. Ponikowski P, Voors AA, Anker SD, et al. 2016 ESC guidelines for the diagnosis and treatment of acute and chronic heart failure: the Task Force for the diagnosis and treatment of acute and chronic heart failure of the European Society of Cardiology (ESC). Developed with the special contribution of the Heart Failure Association (HFA) of the ESC. Eur J Heart Fail 2016;18:891-975.

4. Yancy CW, Jessup M, Bozkurt B, et al. 2013 ACCF/AHA guideline for the management of heart failure: a report of the American College of Cardiology Foundation/American Heart Association Task Force on Practice Guidelines. J Am Coll Cardiol 2013;62:e147-e239.

5. Drazner MH, Rame JE, Stevenson LW, Dries DL. Prognostic importance of elevated jugular venous pressure and a third heart sound in patients with heart failure. $\mathrm{N}$ Engl J Med 2001;345:574-581.

6. Binanay C, Califf RM, Hasselblad V, et al. Evaluation study of congestive heart failure and pulmonary artery catheterization effectiveness: the ESCAPE trial. JAMA 2005;294:1625-1633.

7. Ling HZ, Flint J, Damgaard M, et al. Calculated plasma volume status and prognosis in chronic heart failure. Eur J Heart Fail 2015;17:35-43.

8. Chung ES, O’Brien TM, Menon S, Bartone C, Mazur W, Kereiakes DJ. A pilot study of target weight guided treatment in acute heart failure using ultrafiltration or usual care: effect on sodium removal. Korean Circ J 2014;44:156161.

9. Yoo BS, Park JJ, Choi DJ, et al. Prognostic value of hyponatremia in heart failure patients: an analysis of the clinical characteristics and outcomes in the relation with serum sodium level in Asian Patients Hospitalized for 
Heart Failure (COAST) study. Korean J Intern Med 2015; 30:460-470.

10. Stevenson LW. Are hemodynamic goals viable in tailoring heart failure therapy? Hemodynamic goals are relevant. Circulation 2006;113:1020-1027.

11. Maisel AS, Krishnaswamy P, Nowak RM, et al. Rapid measurement of B-type natriuretic peptide in the emergency diagnosis of heart failure. N Engl J Med 2002;347:161-167.

12. Furstenberg A, Davenport A. Comparison of multifrequency bioelectrical impedance analysis and dual-energy X-ray absorptiometry assessments in outpatient hemodialysis patients. Am J Kidney Dis 2011;57:123-129.

13. Kim M, Shinkai S, Murayama H, Mori S. Comparison of segmental multifrequency bioelectrical impedance analysis with dual-energy X-ray absorptiometry for the assessment of body composition in a community-dwelling older population. Geriatr Gerontol Int 2015;15:1013-1022.

14. Okamoto M, Fukui M, Kurusu A, et al. Usefulness of a body composition analyzer, InBody 2.0, in chronic hemodialysis patients. Kaohsiung J Med Sci 2006;22:207-210.

15. Di Somma S, De Berardinis B, Bongiovanni C, Marino R, Ferri E, Alfei B. Use of BNP and bioimpedance to drive therapy in heart failure patients. Congest Heart Fail 2010; 16 Suppl 1:S56-S61.

16. Hara N, Iwasa M, Iwata K, et al. Value of the extracellular water ratio for assessment of cirrhotic patients with and without ascites. Hepatol Res 2009;39:1072-1079.

17. Mulasi U, Kuchnia AJ, Cole AJ, Earthman CP. Bioimpedance at the bedside: current applications, limitations, and opportunities. Nutr Clin Pract 2015;30:180-193.

18. Parrinello G, Paterna S, Di Pasquale P, et al. The usefulness of bioelectrical impedance analysis in differentiating dyspnea due to decompensated heart failure. J Card Fail 2008;14:676-686.

19. Ho KK, Anderson KM, Kannel WB, Grossman W, Levy D. Survival after the onset of congestive heart failure in Framingham Heart Study subjects. Circulation 1993; 88:107-115.

20. Gibson AL, Holmes JC, Desautels RL, Edmonds LB, Nuudi L. Ability of new octapolar bioimpedance spectroscopy analyzers to predict 4-component-model percentage body fat in Hispanic, black, and white adults. Am J Clin Nutr 2008;87:332-338.

21. Ling CH, de Craen AJ, Slagboom PE, et al. Accuracy of direct segmental multi-frequency bioimpedance analysis in the assessment of total body and segmental body composition in middle-aged adult population. Clin Nutr 2011;30:610-615.

22. Bedogni G, Malavolti M, Severi S, et al. Accuracy of an eight-point tactile-electrode impedance method in the assessment of total body water. Eur J Clin Nutr 2002;56:1143-1148.

23. Cha K, Chertow GM, Gonzalez J, Lazarus JM, Wilmore DW. Multifrequency bioelectrical impedance estimates the distribution of body water. J Appl Physiol (1985) 1995; 79:1316-1319.

24. Chong JU, Nam S, Kim HJ, et al. Exploration of fluid dynamics in perioperative patients using bioimpedance analysis. J Gastrointest Surg 2016;20:1020-1027.

25. Fanestil DD. Compartmentation of body water. In: Narins RG, ed. Clinical Disorders of Fluid and Electrolyte Metabolism. New York: McGraw-Hill, 1994:3-20.

26. Verbalis JG. Disorders of body water homeostasis. Best Pract Res Clin Endocrinol Metab 2003;17:471-503.

27. Miller WL, Borgeson DD, Grantham JA, Luchner A, Redfield MM, Burnett JC Jr. Dietary sodium modulation of aldosterone activation and renal function during the progression of experimental heart failure. Eur J Heart Fail 2015;17:144-150.

28. Solomonica A, Burger AJ, Aronson D. Hemodynamic determinants of dyspnea improvement in acute decompensated heart failure. Circ Heart Fail 2013;6:53-60.

29. Nakagawa O, Ogawa $Y$, Itoh $H$, et al. Rapid transcriptional activation and early mRNA turnover of brain natriuretic peptide in cardiocyte hypertrophy: evidence for brain natriuretic peptide as an "emergency" cardiac hormone against ventricular overload. J Clin Invest 1995;96:12801287.

30. Maeda K, Tsutamoto T, Wada A, Hisanaga T, Kinoshita M. Plasma brain natriuretic peptide as a biochemical marker of high left ventricular end-diastolic pressure in patients with symptomatic left ventricular dysfunction. Am Heart J 1998;135:825-832.

31. Gheorghiade M, Follath F, Ponikowski P, et al. Assessing and grading congestion in acute heart failure: a scientific statement from the acute heart failure committee of the heart failure association of the European Society of Cardiology and endorsed by the European Society of Intensive Care Medicine. Eur J Heart Fail 2010;12:423-433.

32. Berger R, Moertl D, Peter S, et al. N-terminal pro-B-type natriuretic peptide-guided, intensive patient management in addition to multidisciplinary care in chronic 
heart failure a 3-arm, prospective, randomized pilot study. J Am Coll Cardiol 2010;55:645-653.

33. Abraham WT, Adamson PB, Bourge RC, et al. Wireless pulmonary artery haemodynamic monitoring in chronic heart failure: a randomised controlled trial. Lancet 2011;377:658-666.

34. Booth J, Pinney J, Davenport A. The effect of vascular access modality on changes in fluid content in the arms as determined by multifrequency bioimpedance. Nephrol Dial Transplant 2011;26:227-231.

35. Bogonez-Franco P, Nescolarde L, Bragos R, Rosell-Ferrer $\mathrm{J}$, Yandiola I. Measurement errors in multifrequency bioelectrical impedance analyzers with and without impedance electrode mismatch. Physiol Meas 2009;30:573-587.

36. Taylor AE. Capillary fluid filtration. Starling forces and lymph flow. Circ Res 1981;49:557-575.
37. Jacob M, Chappell D. Reappraising Starling: the physiology of the microcirculation. Curr Opin Crit Care 2013;19:282-289.

38. Martin-Du Pan RC, Benoit R, Girardier L. The role of body position and gravity in the symptoms and treatment of various medical diseases. Swiss Med Wkly 2004;134:543551.

39. Man IO, Glover K, Nixon P, Poyton R, Terre R, Morrissey MC. Effect of body position on foot and ankle volume in healthy subjects. Clin Physiol Funct Imaging 2004;24:323326.

40. Felker GM, Teerlink JR. Diagnosis and management of acute heart failure. In: Mann D, Zipes D, Libby P, Bonow R, eds. Braunwald's Heart Disease. 1oth ed. Vol. 1. Philadelphia (PA): Elsevier, 2015:484-491. 
Supplementary Table 1. Baseline characteristics according to the diagnosis of AHF among non-dyspnea, AHF, and non-AHF group

\begin{tabular}{|c|c|c|c|}
\hline Characteristic & Non-dyspnea $(n=50)$ & $\operatorname{AHF}(\mathrm{n}=50)$ & Non-AHF $(n=50)$ \\
\hline \multicolumn{4}{|l|}{ Demographic data } \\
\hline Age, yr & $67.0 \pm 11.6$ & $70.2 \pm 11.3$ & $66.1 \pm 11.6$ \\
\hline$\geq 65 \mathrm{yr}, \%$ & 62.0 & 66.0 & 58.0 \\
\hline Men, \% & 58.0 & 50.0 & 52.0 \\
\hline Body mass index, $\mathrm{kg} / \mathrm{m}^{2}$ & $23.8 \pm 3.2$ & $24.2 \pm 4.1$ & $24.6 \pm 3.4$ \\
\hline \multicolumn{4}{|l|}{ Past medical history, \% } \\
\hline Diabetes mellitus & 20.0 & 34.0 & 14.0 \\
\hline Hypertension & 56.0 & 50.0 & 54.0 \\
\hline $\begin{array}{l}\text { Chronic kidney disease and end stage renal } \\
\text { disease }\end{array}$ & 2.0 & $24.0^{\mathrm{a}}$ & 12.0 \\
\hline Liver cirrhosis & 2.0 & 0 & 4.0 \\
\hline Atrial fibrillation & 2.0 & $24.0^{\mathrm{a}}$ & 4.0 \\
\hline \multicolumn{4}{|l|}{ Laboratory findings } \\
\hline Leukocyte, / $\mu \mathrm{L}$ & $7,763.4 \pm 2,382.0$ & $7,701.8 \pm 3,412.3$ & $7,680.5 \pm 4,401.4$ \\
\hline Hemoglobin, mg/dL & $13.0 \pm 2.6$ & $11.8 \pm 2.4^{\mathrm{a}}$ & $12.3 \pm 2.6$ \\
\hline Platelet, $\times 10^{3} / \mu \mathrm{L}$ & $223 \cdot 5 \pm 99 \cdot 3$ & $176.3 \pm 97.8^{a}$ & $195.2 \pm 81.6$ \\
\hline Blood urea nitrogen, mg/dL & $16.2 \pm 7.5$ & $23.7 \pm 22.4^{a}$ & $18.7 \pm 13.8$ \\
\hline Creatinine, mg/dL & $1.0 \pm 0.7$ & $1.8 \pm 2.1^{\mathrm{a}}$ & $1.3 \pm 1.8$ \\
\hline Glomerular filtration rate, $\mathrm{mL} / \mathrm{min} / 1.73 \mathrm{~m}^{2}$ & $82.4 \pm 30.4$ & $56.0 \pm 29.1^{b}$ & $71.7 \pm 26.8$ \\
\hline Sodium, mEq/L & $140.3 \pm 2.8$ & $138.2 \pm 5.0^{\mathrm{a}}$ & $140.5 \pm 2.4$ \\
\hline Protein, g/dL & $7.14 \pm 0.67$ & $6.52 \pm 0.73^{b}$ & $6.95 \pm 0.59$ \\
\hline Albumin, g/dL & $3.94 \pm 0.69$ & $3.64 \pm 0.48^{a}$ & $3.93 \pm 0.52$ \\
\hline B-natriuretic peptide, $\mathrm{pg} / \mathrm{mL}$ & NA & $1,108 . \circ(288.0-2,372.5)$ & $34.5(17.5-90.3)$ \\
\hline \multicolumn{4}{|l|}{ Vital sign } \\
\hline Systolic blood pressure, $\mathrm{mmHg}$ & $146.4 \pm 28.6$ & $142.4 \pm 28.5$ & $139.6 \pm 33.7$ \\
\hline Diastolic blood pressure, $\mathrm{mmHg}$ & $83.8 \pm 16.5$ & $81.6 \pm 17.0$ & $80.3 \pm 19.2$ \\
\hline Heart rate, /min & $80.0 \pm 13.7$ & $93.7 \pm 22.5^{b}$ & $83.3 \pm 21.4$ \\
\hline Respiratory rate, /min & $18.9 \pm 2.9$ & $20.6 \pm 3.2^{\mathrm{a}}$ & $19.4 \pm 2.5$ \\
\hline \multicolumn{4}{|l|}{ Echocardiographic data } \\
\hline $\mathrm{E}, \mathrm{m} / \mathrm{sec}$ & $0.7 \pm 0.2$ & $1.0 \pm 0.3^{b}$ & $0.7 \pm 0.2$ \\
\hline EDT, msec & $202.4 \pm 52.4$ & $159.6 \pm 46.7^{b}$ & $199.2 \pm 57.7$ \\
\hline $\mathrm{e}^{\prime}, \mathrm{cm} / \mathrm{sec}$ & $6.9 \pm 2.2$ & $6.1 \pm 2.5$ & $7.1 \pm 2.4$ \\
\hline $\mathrm{E} / \mathrm{e}^{\prime}$ & $9.8 \pm 3 \cdot 3$ & $19.4 \pm 8.4^{b}$ & $9.7 \pm 2.7$ \\
\hline Left atrium diameter, $\mathrm{mm}$ & $40.8 \pm 10.5$ & $51.3 \pm 15.0^{b}$ & $41.1 \pm 6.6$ \\
\hline LV ejection fraction, \% & $59 \cdot 9 \pm 5.5$ & $47.5 \pm 14.4^{b}$ & $58.8 \pm 5 \cdot 5$ \\
\hline LV internal diameter in diastole, $\mathrm{mm}$ & $47.2 \pm 3.7$ & $53 \cdot 5 \pm 9.8^{b}$ & $48.3 \pm 4.4$ \\
\hline LV internal diameter in systole, $\mathrm{mm}$ & $30.2 \pm 3.8$ & $37.6 \pm 10.6^{b}$ & $31.1 \pm 4.1$ \\
\hline LV interventricular septum thickness, $\mathrm{mm}$ & $9 \cdot 3 \pm 1.6$ & $9.3 \pm 2.1$ & $8.9 \pm 1.7$ \\
\hline LV posterior wall thickness, $\mathrm{mm}$ & $8.8 \pm 1.3$ & $9.8 \pm 5.6$ & $8.3 \pm 1.4$ \\
\hline LV mass index, $\mathrm{g} / \mathrm{m}^{2}$ & $88.7 \pm 17.6$ & $112.9 \pm 49.1^{\mathrm{a}}$ & $85.6 \pm 19.8$ \\
\hline
\end{tabular}

Values are presented as mean \pm standard deviation or median (interquartile range).

AHF, acute heart failure; NA, not applicable; E, peak velocity of transmitral early diastolic left ventricular filling; EDT, E-deceleration time; e', early diastolic annular velocity; LV, left ventricle.

${ }^{a} p<0.05$ compared with non-dyspnea group.

${ }^{\mathrm{b}} p<0.001$ compared with non-dyspnea group. 
Park CS, et al. AHF evaluation with bio-impedance analysis

Supplementary Table 2. Body fluid distribution according to the diagnosis of AHF among non-dyspnea, AHF, and non-AHF group

\begin{tabular}{lccc}
\hline Variable & Non-dyspnea $(\mathrm{n}=50)$ & AHF $(\mathrm{n}=50)$ & Non-AHF $(\mathrm{n}=50)$ \\
\hline Weight, kg & $63.1 \pm 12.1$ & $62.6 \pm 13.0$ & $63.0 \pm 11.0$ \\
TBW, L & $33.3 \pm 7.5$ & $33.7 \pm 8.3$ & $32.0 \pm 6.6$ \\
ICW, L & $20.4 \pm 4.9$ & $19.8 \pm 5.0$ & $19.6 \pm 4.6$ \\
ECW, L & $12.9 \pm 2.7$ & $13.9 \pm 3.5$ & $12.3 \pm 2.3$ \\
ECW/TBW & $0.389 \pm 0.013$ & $0.412 \pm 0.017^{\mathrm{a}}$ & $0.388 \pm 0.023$ \\
ECW/TBW of upper extremities & $0.382 \pm 0.007$ & $0.388 \pm 0.013^{\mathrm{b}}$ & $0.380 \pm 0.007$ \\
ECW/TBW of trunk & $0.389 \pm 0.014$ & $0.413 \pm 0.017^{\mathrm{a}}$ & $0.389 \pm 0.020$ \\
ECW/TBW of lower extremities & $0.392 \pm 0.016$ & $0.419 \pm 0.020^{\mathrm{a}}$ & $0.390 \pm 0.026$ \\
\hline
\end{tabular}

Values are presented as mean \pm standard deviation.

AHF, acute heart failure; TBW, total body water; ICW, intracellular water; ECW, extracellular water.

${ }^{a} p<0.001$ compared with non-dyspnea group.

$\mathrm{b} p<0.05$ compared with non-dyspnea group. 


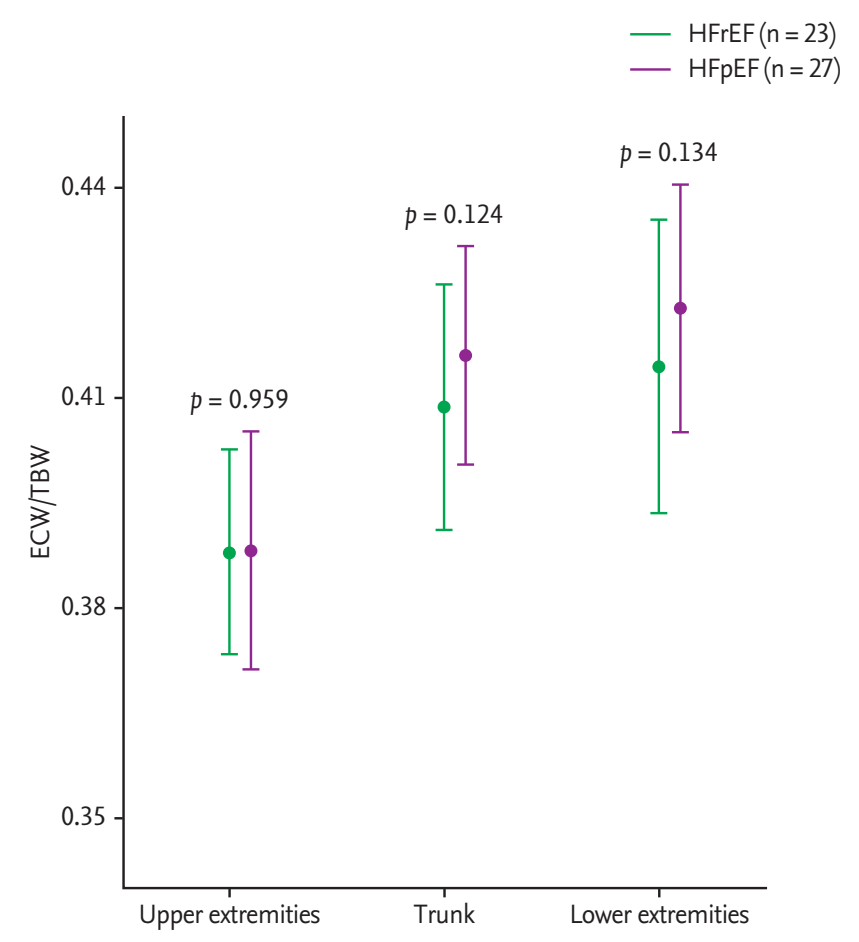

Supplementary Figure 1. Comparison of water distribution between patients with HFrEF and HFpEF. There was no significant difference of ECW/TBW between HFrEF patients and HFpEF patients along the body segments. ECW, extracellular water; TBW, total body water; HFrEF, heart failure with reduced ejection fraction; HFpEF, heart failure with preserved ejection fraction. 